\title{
Biodegradable Plasticizing Composition for Plastics with a Limited Service Life ${ }^{\dagger}$
}

\author{
Aliya K. Mazitova, Irina N. Vikhareva * \\ Applied and Natural Sciences Department, Ufa State Petroleum Technological University, Mendeleeva St. 195, \\ 450080 Ufa, Russia; elenaasf@yandex.ru (A.K.M.) \\ * Correspondence: irina.vikhareva2009@yandex.ru; Tel.: +7(347)2420370 \\ + Presented at the First International Conference on “Green” Polymer Materials 2020, 5-25 November 2020; \\ Available online: https://cgpm2020.sciforum.net/.
}

Published: 4 November 2020

\begin{abstract}
The widespread use of synthetic polymers has led to the accumulation of their wastes, of which only about $10 \%$ is processed, the rest is accumulated in nature, and decomposition in natural conditions occurs for a long time. Therefore, the development of biodegradable plastics is important. Today, plastics based on plant raw materials do not compete with traditional plastics, since they have unsatisfactory operational properties, and their production technologies consume a significant amount of energy and water and are characterized by emissions of pollutants. The development of composites from traditional plastics with biodegradable additives, which are completely compostable in nature, is relevant. Plasticizers, as the main part of plastic, are the most convenient way to model the biodegradability of the composite. When developing biodegradable plastic, it is important to ensure a certain service life. For this purpose, biocides with a limited duration are used. Zinc compounds are known among them. Therefore, in the presence of catalyst $\mathrm{ZnO}$, a new non-toxic plasticizer, decyl phenoxyethyl adipate, was obtained in $89.5 \%$ yield. Method of its co-production with zinc compound has been developed. For the use of decyl phenoxyethyl adipate in PVC composites by TGA and DSC (Mettler Toledo), thermal stability, crystallization and melting temperatures of the plasticizer, enthalpy values of these processes were studied; PVC compatibility is estimated by the critical dissolution temperature of the polymer in the plasticizer. Effect of zinc compound formed in situ as biocide on biodegradation of PVC film samples with developed plasticizer is investigated. As a result of the tests, the obtained zinc compound in an amount of $0.3 \%$ in the formulation of the PVC composition provides a biocidal effect for a certain period of operation of the obtained plastic, after which the biodegradation process begins.
\end{abstract}

Keywords: adipate plasticizer; biodegradable; biocide; zinc compound; polyvinyl chloride

\section{Introduction}

The convenience, practicability and accessibility of plastic materials based on synthetic polymers have contributed to the accumulation of significant amounts of plastic waste, which according to economic research is considered not only an environmental problem, but also the main risk that threatens the stability of the global economic complex [1].

Initially, the idea of creating synthetic polymers was to develop materials that are extremely resistant to environmental factors. In modern conditions, a new approach has been formed: It is necessary to obtain polymers that maintain performance only during the consumption period, and then undergo physicochemical and biological transformations under the influence of environmental factors and are easily included in the metabolic processes of natural biosystems [2]. 
It was with the use of natural biodegradable ingredients as raw materials and the production of polymers similar to natural ones that the plastics industry was formed [3]. For example, the first food packages were based on cellulose hydrate or cellulose acetate.

It is known that plastics based on plant raw materials: wood, starch, polysaccharides decompose into absolutely safe components, such as water, carbon dioxide, biomass and other natural compounds, that is, provide absolute environmental friendliness of recycling processes [4]. In addition, plant raw materials can resume indefinitely.

However, production of natural polymers in comparison with polymers based on petrochemical raw materials has higher costs, consumes much more energy and water, is characterized by emissions of pollutants, and products do not provide satisfactory performance [5].

Currently, two directions of biodegradable polymer materials creation are actively developing: Directed synthesis of biodegradable plastics and introduction of biodegradable additives into the synthetic polymer macromolecule [6].

The first method is an expensive process with special equipment and process requirements. It is also necessary to take into account that the leading positions of polyolefins and polyvinyl chloride in annual sales volumes indicate the promising development of composites based on them [7].

The mechanical properties of composites reinforced with natural fibers depend on the nature of the binder and its physical and mechanical characteristics. Since natural fibers are hydrophilic in nature and have a high moisture content, the degree of adhesion at the hydrophobic matrix-fiber interface is low. In order to improve adhesion, the surface of fibers and matrices are modified, resulting in additional steps in the manufacturing process and, accordingly, in costs [8].

Polymer composites with synthetic additives promoting biodegradation are characterized by higher tensile strength, lower water absorption and, in general, higher performance characteristics [8].

It is very promising to use suitable plasticizers as a biodegradable additive, since their amount in the polymer composition is more than $40 \%$ [8].

The polymer materials are adversely affected by numerous aggressive factors. And often they aggravate each other. Therefore, when developing biodegradable plastic, it is important to ensure the stability of its physical, mechanical and operational qualities for a certain service life. Therefore, the complex biocidal action is of considerable interest [9]. Among the general requirements for biocides are high efficiency of biocidal action, availability and relatively low cost, solubility in water, instability in natural conditions, ease of use, environmental safety and low toxicity to humans [9]. Therefore, it is convenient to use time-limited biocides, for example zinc compounds.

Due to the high biological activity, relatively low cost and environmental safety, zinc compounds are very promising for use as biocidal additives because they exhibit high antibacterial activity against a wide range of bacteria and fungi [10-12].

In view of this, the novel ester plasticizer of polyvinyl chloride based on an adipic acid ester has been prepared for use in a PVC composition as a biodegradable additive. Zinc oxide was used to catalyze the reaction, from which zinc phenoxyethyl adipate was obtained in situ. Further, complex studies were carried out aimed at studying the features of biodegradation of the developed polymer compositions.

\section{Experiments}

\subsection{Starting Materials}

All the chemicals were used as received with the content of the main substance not less than 98\%. Polyvinyl chloride (Joint Stock Company "Caustic," Sterlitamak, Russia): We used industrial samples of suspension polyvinyl chloride PVC 7059M.

\subsection{Synthesis Methods}

2.2.1. The synthesis of Decyl Phenoxyethyl Adipate (DPEA) 
First, $150 \mathrm{~mL}$ of toluene and $158 \mathrm{~g} \mathrm{(} 1 \mathrm{~mol})$ of decanol were charged into the reaction flask and stirred until the reagents were completely dissolved. Then, $3.0 \mathrm{~g}$ ( $1 \%$ by weight) of zinc oxide and $146 \mathrm{~g}(1 \mathrm{~mol})$ of adipic acid were added, and the temperature was slowly raised to $118^{\circ} \mathrm{C}$. Stirring was continued for $1.5 \mathrm{~h}$. The end of the reaction was determined by the amount of released water.

Then, without isolating the monoester, it was esterified with phenoxyethanol (138 g) taken in the molar ratio monoester: Alcohol =1:0.93. Boiling was continued for $2 \mathrm{~h}$. The reaction mixture was cooled, and the product was filtered and dried at $128^{\circ} \mathrm{C}$. The yield of the light powder product was $363 \mathrm{~g}$ (89.5\% of theoretical). The product was a mixture of decyl phenoxyethyl adipate (337.6 g) plasticizer and zinc decyl adipate in an amount of $25.4 \mathrm{~g}$.

\subsection{Methods of Analysis}

The analysis of physicochemical parameters of the obtained compound was carried out in accordance with state standard 8728-88 Plasticizers. Specifications [13]. For this, the following indicators were determined: Acid number, ester number, mass fraction of volatile substances.

Density was determined according to state standard 18329-2014 Liquid resins and plasticizers. Methods for determination of density [14].

The refractive index was determined on an IRF-22 refractometer according to state standard 18995.2-73 Liquid chemical products. Method for determination of refractive index [15].

For thermogravimetric analysis, a TGA/DSC-1 device (Mettler Toledo company, Greifensee, Switzerland) was used. The temperature range of the device was $25-1100{ }^{\circ} \mathrm{C}$. The maximum volume of the test sample did not exceed $900 \mu \mathrm{L}$. The maximum heating rate of the sample was $150 \mathrm{~K} / \mathrm{min}$. The cooling rate of the device was $20 \mathrm{~K} / \mathrm{min}$. Measurement accuracy $\pm 0.3 \mathrm{~K}$.

A sample of the test sample $(5-15 \mathrm{mg})$ was placed in an aluminum crucible with a volume of 70 $\mu \mathrm{L}$. The measurements were carried out in the temperature range from $25^{\circ} \mathrm{C}$ to $500{ }^{\circ} \mathrm{C}$ at different heating rates, with atmosphere-air, nitrogen. Processing of the results was carried out using a computer. A curve was displayed on the computer screen as a function of the mass of the sample versus temperature (TGA curve), as well as a DSC curve characterizing the thermal effects that occur during the destruction of the test sample.

The tensile breaking stress $\left(\delta_{b}\right)$ was determined according to state standard 11262-2017 [16] and the elongation at rupture $(\varepsilon)$ of PVC films was determined according to state standard 14236-81 [17] on the rupture machine RM-250.

Water absorption $\Delta \mathrm{m}(\%)$ was evaluated by changing the weight of samples when exposed to distilled water at a temperature of $(23 \pm 2)^{\circ} \mathrm{C}$ for certain time intervals [18].

\section{Results and Discussion}

Decyl phenoxyethyl adipate (DPEA) together with zinc decyl adipate was obtained in two stages (Scheme 1).

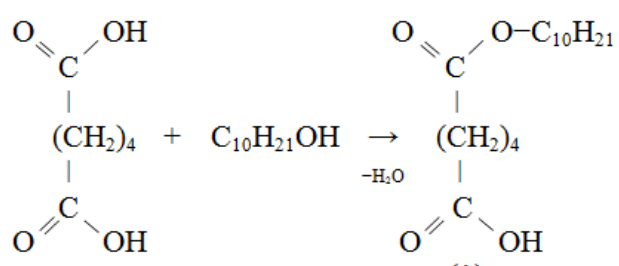

(1)
(1)<smiles>CCCCCCCCC(=O)OCCOc1ccccc1</smiles>

Scheme 1. Synthesis of decyl phenoxyethyl adipate (DPEA).

In the first stage, an adipic acid monoester was prepared by reacting decanol with adipic acid, taken in an equimolar ratio, in the presence of an azeotropic water-carrying agent toluene and zinc oxide catalyst in an amount of $1 \mathrm{wt} \%$ from total component loading. Then, without isolating the monoester, it was esterified with the calculated amount of phenoxyethanol. The end of the reaction was determined by the amount of released water and the acid number of the esterificate. The 
reaction mixture was cooled, and the product was filtered and dried at $125^{\circ} \mathrm{C}$. As a result, adipic acid ester and zinc decyl adipate were obtained together. For research, the bulk of the obtained product was thoroughly washed from the zinc compound and pure ester was obtained. Physicochemical properties of the obtained adipic acid ester: Molecular Weight - 406, acid number $0.1 \mathrm{mg} \mathrm{KOH} / \mathrm{g}$, ester number $-275 \mathrm{mg} \mathrm{KOH} / \mathrm{g}$, $\mathrm{d}^{20}{ }_{4}-0.9957$.

The residue of the resulting product as a mixture of the ester and the zinc compound in the form of a plasticizing composition was used to study the biodegradation process.

To study the possibility of practical use of a plasticizer in PVC composites, it is important to meet the modern requirements of the following indicators: Thermal stability, melting and crystallization temperatures, compatibility with the polymer.

The thermal stability of the plasticizers was studied by thermogravimetry using a TGA-DSC-combined thermal analysis instrument (Mettler Toledo) in the temperature range of $20-500{ }^{\circ} \mathrm{C}$ at a heating rate of $5{ }^{\circ} \mathrm{C} / \mathrm{min}$. For comparison, a sample of industrial plasticizer di-2-ethylhexylphthalate (DOP) is usually used.

To this end, weight reduction was also evaluated by heating the plasticizer to temperatures of $180^{\circ} \mathrm{C}$ and $200{ }^{\circ} \mathrm{C}$ corresponding to the processing temperature interval of PVC compositions $(\Delta \mathrm{m})$ (Table 1).

Table 1. The results of the thermal analysis of plasticizers.

\begin{tabular}{cccccc}
\hline Sample & \multicolumn{5}{c}{ Characteristics } \\
\hline & \multicolumn{3}{c}{ Temperature, $^{\circ} \mathbf{C}$} & \multicolumn{2}{c}{$\Delta \mathbf{m}, \%$} \\
\cline { 2 - 6 } & Beginning & Maximal Value & End & at $\mathbf{1 8 0}{ }^{\circ} \mathbf{C}$ & at $\mathbf{2 0 0}{ }^{\circ} \mathbf{C}$ \\
\hline DPEA & 101.35 & 316.50 & 375.44 & 0.8 & 1.6 \\
DOP & 134.07 & 284.83 & 497.89 & 1.0 & 1.9 \\
\hline
\end{tabular}

From the results of thermal analysis, it follows that the decomposition of the studied DPEA plasticizer occurs in the temperature range from 101 to $375{ }^{\circ} \mathrm{C}$ (Table 1).

It should also be noted that the parameter $\Delta \mathrm{m}$ is relatively low for the obtained DPEA plasticizer at temperatures of 180 and $200{ }^{\circ} \mathrm{C}$, which characterizes the low content of volatile impurities in the product that can be released during the processing of the plasticized PVC composition at the molding of materials and products.

In contrast to DOP, the synthesized plasticizer is a solid product; therefore, melting and crystallization temperatures are important for its practical use. These indicators, as well as the enthalpy of these processes, were determined by differential scanning calorimetry on a DSC-1 instrument (Mettler Toledo) in the temperature range from -50 to $115^{\circ} \mathrm{C}$ at a heating/cooling rate of $5{ }^{\circ} \mathrm{C} / \mathrm{min}$.

An endothermic peak corresponding to the melting process with a maximum of $\mathrm{T}_{\mathrm{m}}=84.0^{\circ} \mathrm{C}$ is fixed on the thermogram of the plasticizer in the heating mode in the temperature range of $75-87^{\circ} \mathrm{C}$. When the sample is cooled in the temperature range of $4-12{ }^{\circ} \mathrm{C}$, there is an exothermic peak of low intensity with a maximum of $\mathrm{T}_{\mathrm{cr}}=8^{\circ} \mathrm{C}$ (Table 2$)$.

Table 2. DSC analysis of decyl phenoxyethyl adipate plasticizer.

\begin{tabular}{|c|c|c|c|c|c|c|c|c|}
\hline \multirow{3}{*}{ Sample } & \multicolumn{4}{|c|}{ Endotherm Characteristics } & \multicolumn{4}{|c|}{ Exotherm Characteristics } \\
\hline & \multicolumn{3}{|c|}{ Temperature, ${ }^{\circ} \mathrm{C}$} & \multirow[b]{2}{*}{$\begin{array}{c}\Delta \mathbf{H}_{\mathrm{m}} \\
\mathrm{J} / \mathrm{g}\end{array}$} & \multicolumn{3}{|c|}{ Temperature $^{\circ} \mathrm{C}$} & \multirow[b]{2}{*}{$\begin{array}{c}\Delta \mathbf{H}_{\mathrm{cr},} \\
\mathrm{J} / \mathrm{g}\end{array}$} \\
\hline & Beginning & $\begin{array}{c}\text { Maximal } \\
\text { Value }\end{array}$ & End & & Beginning & $\begin{array}{c}\text { Maximal } \\
\text { Value }\end{array}$ & End & \\
\hline DPEA & 75.61 & 84.00 & 86.88 & -67.78 & 11.31 & 8.00 & 4.67 & 131.24 \\
\hline
\end{tabular}

An important parameter determining the possibility of using a plasticizer in polymer compositions is its compatibility with the polymer. One of the methods for determining the 
compatibility of a plasticizer with PVC is an assessment of the critical temperature of polymer dissolution in a plasticizer using a critical temperature $\mathrm{T}_{\mathrm{c}}$.

It was found that the dissolution temperature of PVC in the DPEA plasticizer is noticeably (by $56^{\circ} \mathrm{C}$ ) higher than that in DOP (Table 3), which indicates the lower compatibility of this plasticizer with the polymer. Apparently, the obtained compound can be classified as secondary plasticizers, which are partially compatible with the polymer and used as a mixture with a primary plasticizer, for example, with DOP.

Table 3. The results of determining the critical temperature of the dissolution of plasticizers.

\begin{tabular}{cc}
\hline Plasticizer & $\mathbf{T}_{\mathbf{c}}{ }^{\circ}{ }^{\circ} \mathbf{C}$ \\
\hline DOP & 113 \\
DPEA & 169 \\
Mixture DOP : DPEA $(5: 1)$ & 119 \\
\hline
\end{tabular}

Therefore, for further work, a mixture of DOP with synthesized plasticizer DPEA in the ratio of 5:1 (wt.) was obtained. The compatibility of PVC with this mixture of plasticizers $\left(\mathrm{T}_{\mathrm{c}}=119{ }^{\circ} \mathrm{C}\right)$ is slightly lower than with DOP (Table 5); however, this mixture can be used as part of PVC composites.

To study the effect of the obtained DPEA plasticizer and the developed zinc decyl adipate additive on the biodegradation of PVC plasticates, the following formulations were prepared:

1 - 100 parts by weight of PVC; 42 parts by weight of the plasticizer DOP; 3 parts by weight of calcium stearate stabilizer;

2 - 100 parts by weight of PVC; 42 parts by weight of a mixture of plasticizers DOP:DPEA in a ratio of 35:7; 3 parts by weight of calcium stearate stabilizer;

3 - 100 parts by weight of PVC; 35 parts by weight of a plasticizers DOP; 7 parts by weight of a plasticizing composition with DPEA and zinc compound; 3 parts by weight of calcium stearate stabilizer.

PVC film samples were obtained by rolling on laboratory rollers. In the work, the study of biodegradation of the obtained samples was carried out while holding them in soil at a depth of 15 cm for 350 days.

Degradation of polymer materials in natural conditions is a complex process, the speed of which is influenced by the structure and properties of the polymer material and the surrounding conditions - humidity, temperature, acidity of the medium, light, as well as contact with the soil and soil type. The ability of PVC plastics to biodegradate under natural conditions is primarily characterized by a change in the mass of samples in water at room temperature (Figure 1).

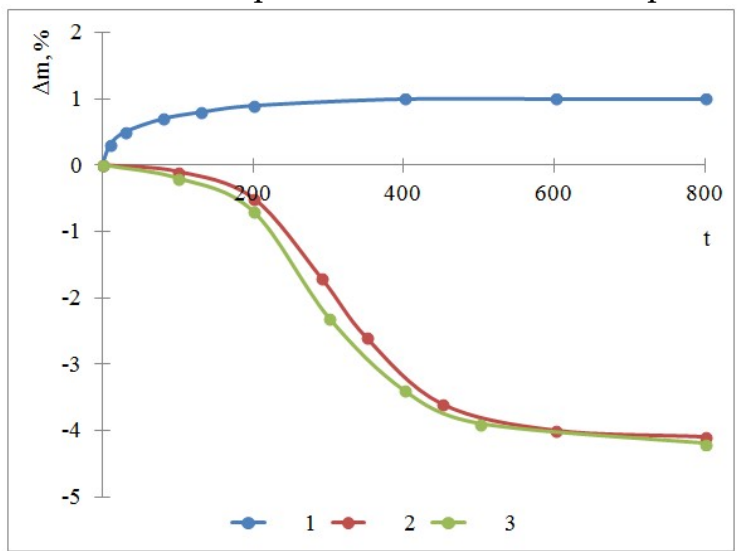

Figure 1. The change in mass $(\Delta \mathrm{m})$ as a function of time (hour) in water for PVC film samples. 
In this case, the change in the weight of the PVC composites 2 and 3 containing the DPEA plasticizer is initially due to the washing out of the adipate plasticizer. Subsequently, the change in mass is the result of two opposite processes: Initially, a slightly greater reduction in the weight of the sample of formulation 3 is probably due to better solubility of zinc carboxylate. The sample corresponding to the composition $\mathbf{1}$ is much less susceptible to weight change because the DOP is incapable of washing out.

Plasticizers included in PVC-based materials are characterized by different resistance to microorganisms. At the same time, the nature of the plasticizer plays an important role. When microorganisms use plasticizers as a carbon source in PVC materials, significant changes in properties are observed [9].

It is known that, unlike phthalate plasticizers, adipate plasticizers are involved in the process of life of various microorganisms, as a result of which acidic products soluble in water are formed. For example, oxalic, succinic acids, which provoke the acceleration of the decomposition process of the material [19-20].

The physical and mechanical properties of the PVC material change significantly due to the degradation and washing out of the DPEA plasticizer in composition 2. Figure 2 shows the nature of the change in the most important operational properties of film materials from the time of action of microorganisms in full-scale tests. The increase in tensile breaking stress and the corresponding decrease in rupture elongation indicates a reduction in film elasticity due to rupture and loss of part of the plasticizer.

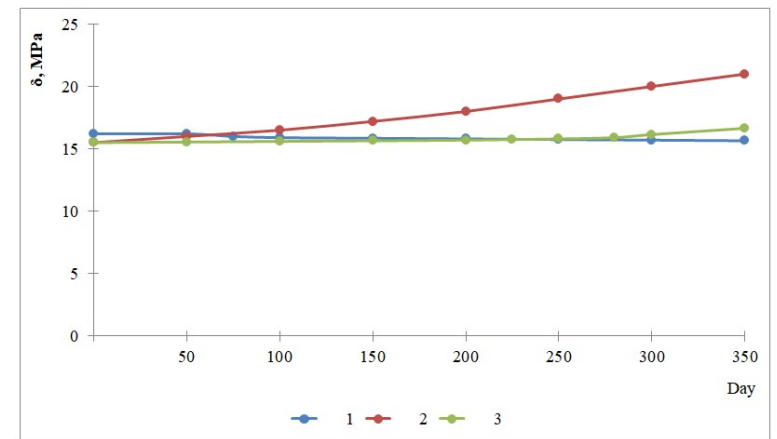

(a)

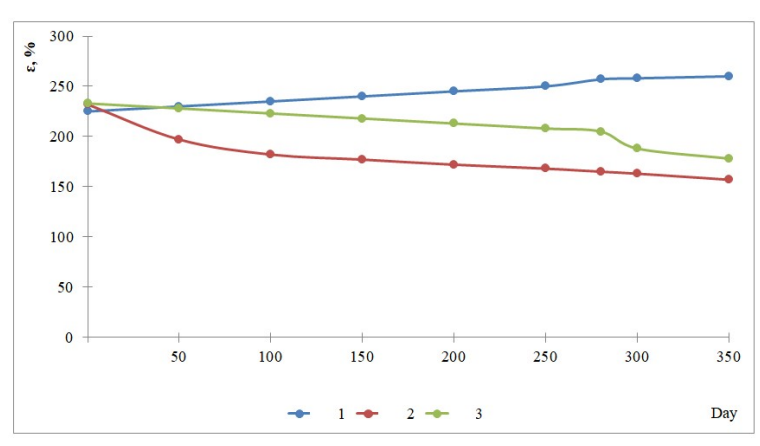

(b)

Figure 2. The change of physical and mechanical properties of plasticized PVC films during full-scale test: (a) Tensile breaking stress; (b) Elongation at break.

For PVC film samples according to the formulation 3, physical and mechanical stability is characteristic at the initial stage. After the expiry of the zinc decyl adipate biocidal additive (280 days), a significant change in film elasticity is observed, due to the influence of a biodegradable adipic acid plasticizer.

Phthalate plasticizers are not a nutrient medium that ensures the life of microorganisms in the soil. Therefore, in the case of the composition 1, as expected, no noticeable changes in the physical and mechanical properties of the PVC film were found. A slight increase in film elasticity of the composition 1, accompanied by a decrease in tensile breaking stress, is likely due to the film's absorption of soil microorganism life products.

\section{Conclusions}

Thus, partial replacement of the industrial plasticizer DOP with a new biodegradable plasticizer decyl phenoxyethyl adipate contributes to accelerating the biodegradation processes of spent PVC products in natural conditions. At the same time, the service life and initial physical and mechanical properties of PVC composites based on the developed plasticizer are not inferior to industrial plastics based on DOP. The new zinc decyl adipate biocidal additive enables to obtain 
biologically decomposable thermoplastic PVC compositions with a controlled service life. Application of the developed plasticizing composition in the composition of PVC plastics is a promising method of reducing the amount of polymer waste and improving the environmental situation.

Acknowledgments: This research received no external funding.

Author Contributions: A.K.M., I.N.V. conceived and designed the experiments, analyzed the data, wrote the paper; I.N.V. performed the experiments.

Conflicts of Interest: The founding sponsors had no role in the design of the study; in the collection, analyses, or interpretation of data; in the writing of the manuscript, and in the decision to publish the results.

\section{Appendix B}

Scheme A1. Synthesis of decyl phenoxyethyl adipate (DPEA). Table A1. The results of the thermal analysis of plasticizers. Table A2. DSC analysis of decyl phenoxyethyl adipate plasticizer. Table A3. The results of determining the critical temperature of the dissolution of plasticizers. Figure A1. The change in mass $(\Delta \mathrm{m})$ as a function of time (hour) in water for PVC film samples. Figure A2. The change of physical and mechanical properties of plasticized PVC films during full-scale tests: (a) Tensile breaking stress; (b) Elongation at break.

\section{References}

1. World Economic Forum. Available online: https://www.weforum.org/events/world-economic-forum-annual-meeting-2016 (accessed on 24 September 2020.

2. Legon'kova, O.A. Thousand and one polymer from biologically resistant to biodegradable; RadioSoft: Moscow, Russia, 2004; $272 \mathrm{p}$.

3. Bocqué, M.; Voirin, C.; Lapinte, V.; et al. Petro-based and bio-based plasticizers: chemical structures to plasticizing properties. Journal of Polymer Science Part A: Polymer Chemistry, 2016, 54, pp. 11-33. DOI: 10.1002/pola.27917.

4. Bozell, J.J. Connecting biomass and petroleum processing with a chemical bridge. Science, 2010, 329 (5991), pp. 522-523. DOI: 10.1126/science.1191662.

5. Álvarez-Chávez, C.R.; Edwards, S.; Moure-Eraso, R.; Geiser, K. Sustainability of bio-based plastics: general comparative analysis and recommendations for improvement. Journal of Cleaner Production, 2012, 23, pp. 47-56. DOI: 10.1016/j.jclepro.2011.10.003.

6. Walker, S.; Rothman, R. Life cycle assessment of bio-based and fossil-based plastic: A review. Journal of Cleaner Production, 2020, 261, 121158 p. DOI: 10.1016/j.jclepro.2020.121158.

7. Jakoby, R. Marketing and Sales in the Chemical Industry in Plastics and Rubbers, 2nd ed.; Wiley-VCH: New York, NY, USA, 2002; 177p.

8. Wickson, E.J.; Grossman, R.F.; Kuirk, R.P. The Development of Compositions Based on PVC; Scientific foundations and technologies: St. Petersburg, Russia, 2009; 608p.

9. Gerasimenko, A.A. Protection against corrosion, aging and bio-damage of machinery, equipment and structures; Machine engineering: Moscow, 1987; 688 p.

10. Jones, N.; Ray, B.; Ranjit, K.T. et al. Antibacterial activity of $\mathrm{ZnO}$ nanoparticle suspensions on a broad spectrum of microorganisms. FEMS Microbiology Letters, 2008, 279 (1), 71p. DOI: 10.1111/j.1574-6968.2007.01012.x.

11. Jalal, R.; Goharshadi, E.K.; Abareshi, M. et al. $\mathrm{ZnO}$ nanofluids: green synthesis, characterization, and antibacterial activity. Materials Chemistry and Physics, 2010, 121 (1), 198p. DOI: 10.1016/j.matchemphys.2010.01.020

12. Seil, J.T.; Webster, T.J. Antimicrobial applications of nanotechnology: methods and literature. International Journal of Nanomedicine, 2012, 7, 2767p. DOI: 10.2147/IJN.S24805.

13. Interstate Standard 8728-88. Plasticizers. Specifications; IPK Publishing house's standards of quality: Moscow, Russia, 2003; 11p.

14. Interstate Standard 18329-2014. Liquid Resins and Plasticizers. Methods for Determination of Density; FSA STANDARTINFORM: Moscow, Russia, 2015; 8p. 
15. Interstate Standard 18995. 2-73. Liquid Chemical Products. Method for Determination of Refractive Index; IPK Publishing house's standards of quality: Moscow, Russia, 1998; 2p.

16. Interstate Standard 11262-2017. Plastics. Tensile test method; FSA STANDARTINFORM: Moscow, Russia, 2015; 20p.

17. Interstate Standard 14236-81. Polymer films. Tensile test method; IPK Publishing house's standards of quality: Moscow, Russia, 1992; 9p.

18. Interstate Standard 4650-2014. Plastics. Methods for the determination of water absorption. FSA STANDARTINFORM: Moscow, Russia, 2015; 17p.

19. Orekhov, D.A.; Vlasova, G.M.; Makarevich, A.V.; Pinchuk, L.S. Biodegradable films based on thermoplastics. Reports of the National Academy of Sciences of Belarus, 2000, 44 (6), pp. 100-103.

20. Suvorova, A.I. Biodegradable systems: thermodynamics, rheological properties and biocorrosion. High-molecular compounds, 2008, 50 (7), pp. 1162-1171.

(C) 2020 by the authors; licensee MDPI, Basel, Switzerland. This article is an open access article distributed under the terms and conditions of the Creative Commons by Attribution (CC-BY) license (http://creativecommons.org/licenses/by/4.0/). 